\title{
A Team Approach to Professional Development and Accountability
}

\author{
Lynne T. Roy, CNMT, FSNMMITS \\ Cedars-Sinai Medical Center, Los Angeles, California
}

Excellent front-line caregivers are often promoted to supervi-
sory positions because of their abilities, knowledge, and supe-
rior communication and critical thinking skills. However, they often
lack knowledge of the 5 essential leadership domains. These
newly appointed supervisors and managers are eager to learn
these new competencies, but their organization is frequently not
able to provide this education. Management and leadership skills
are often learned on the job. Professional development is left up to
the individual. It becomes crucial for upper-management profes-
sionals, as stewards of their organization, to ensure that those in
first-line and middle management are given the opportunity to
develop their skills and advance their careers. In this article, I describe
my journey of organizing and developing a self-directed imaging
leadership team and the success and professional growth that can
be achieved if one remains committed to the goal. This journey
paralleled Bruce Tuckman's description of team development.
As such, this article is formatted to highlight each of these stages.

Key Words: professional development; self-directed teams; stewardship

J Nucl Med Technol 2019; 47:332-335

DOI: 10.2967/jnmt.119.226886

H

ealth caregivers usually start their careers as first-line employees. Therefore, it comes as no surprise that most supervisors, managers, directors, and other middle-management employees have risen through the ranks. Employees who move through the ranks in this fashion have demonstrated the ability and the need to learn and to think critically. They are flexible, adapt well to change, and are exceptional communicators. However, other skills are also needed to manage.

Many books and articles have been written describing the traits, actions, and competencies of leaders $(1,2)$. These books describe several behaviors as being essential to success: self-awareness, the capability to motivate and communicate, the capacity to create a culture of accountability, the ability to make unbiased decisions for the good of the team and the

Received Feb. 21, 2019; revision accepted Jun. 3, 2019.

For correspondence or reprints contact: Lynne T. Roy, Cedars-Sinai Medical Center, 8700 Beverly Blvd., Taper Building. M-335, Los Angeles, CA 90048.

E-mail: roy@cshs.org

Published online Aug. 10, 2019

COPYRIGHT (c) 2019 by the Society of Nuclear Medicine and Molecular Imaging. organization, and the ability to build trust. Most new leaders do not exhibit all these talents. Additional education is needed to augment their innate skills. They rarely get the specific training they need while on the job.

Stewardship is defined as an ethic that embodies the responsible planning and management of resources, including leadership succession. Several years ago, I realized that being a steward of my organization was one of my more important priorities. I took a hard and honest look at the 6 associate directors (ADs) and 17 supervisors in the imaging department. I believed that few of them exhibited the attributes that would allow them to be successful if promoted.

The ADs understood the what and the why of institutional goals and objectives, but they did not know how to execute tactics to meet them. Our supervisors, although well meaning, had their own understanding of the goals and could not see the forest for the trees. They were "independent contractors" working in a silo. All believed that their supervisor colleagues compromised their efficiency and effectiveness.

At the same time, our organization was struggling to realign itself to prepare for the changes in health care due to passage of the Affordable Care Act in 2010. We, like all other health care institutions in the United States, were struggling to decrease costs and increase efficiency. These massive changes resulted in the downsizing of many management positions. Those remaining had to be good at leading, enforcing my belief that my team had to become more skilled at reducing costs and improving departmental productivity, patient safety, and employee engagement.

I began by doing extensive reading on managing, leading, and the power of teams, and I became convinced that the best way for our department to meet the challenges and newly assigned goals was to develop a self-organized team. Highperforming teams have many characteristics $(3,4)$, but the ones I found to be the most important were that they create a learning environment, they focus on the collective mission, they establish their own goals with their own consequences, they challenge the status quo, and they take ownership of their actions and outcomes. They are masters of performance improvement.

\section{FIRST THINGS FIRST}

I started with the management team. This team, comprising me (the executive director) and the $6 \mathrm{ADs}$, met 
biweekly. We prioritized and measured hospital goals and discussed tactics to achieve them. We also focused on policies and procedures. Execution of these tactics was difficult, and getting all ADs to adhere to policies and procedures was a struggle.

Companies that embrace the Six Sigma methodology (5) are thought to be more competitive and able to adapt quickly to market changes better than their non-Six Sigma counterparts. I therefore enrolled the ADs in a green belt course (the term given to an intermediate-level Six Sigma training class), lasting $6 \mathrm{wk}$. This was not a popular decision, but to their credit, they attended and passed.

Concurrently, the management team evaluated the supervisors. Not surprisingly, each AD thought that his or her supervisor was the best. After careful data-driven analysis, the ADs came to the same conclusion: each supervisor had been a high-functioning first-line employee who had little leadership training. In addition, the supervisors did not have a clear understanding of their roll. Most had never had a formal discussion with their AD regarding long-term career paths or goals.

The management team also realized that the supervisors' job descriptions were too task-oriented. Along with the human resources staff, the supervisors rewrote their job descriptions with a focus on goal achievement, customer satisfaction, and employee engagement. Each supervisor would be reviewed by his or her $\mathrm{AD}$ and the executive director. The review was weighted: $80 \% \mathrm{AD}$ and $20 \%$ executive director.

Both the $\mathrm{AD}$ and I met with each supervisor to review the new appraisal tool and to explain the weighted scoring system. This meeting was timed with the current review cycle. The supervisors would be reviewed with the old tool, but next year's appraisal would use the new weighted tool. There were lots of questions and suggestions. Changes were made, and the new form was approved.

\section{IN THE FORMING STAGE}

I am fortunate that my medical center has an active and well-developed organizational development department within its human resources department. The organizational development department was enthusiastic about my vision to develop a self-directed supervisor team. After a lengthy discussion, the organizational development department helped me craft a vision statement. It was simple: "Tap the collective insight and experience of the associate directors and supervisors to address issues, improve processes important to our patients and staff, and professionally develop its members."

I called a meeting of our entire leadership team, which includes the ADs, supervisors, and team leaders. Team leaders in our organization are not considered first-line supervisors. They are nonexempt employees and often are doing assigned work. However, they manage patient flow, breaks, and lunches. I acknowledged the difficult and stressful situations they often found themselves in. I shared the vision statement and the hope that by working together, goals would be attainable and some of the barriers that had been created between teams would be eliminated. To this end, the supervisors and team leaders would be forming a supervisor action team to work together to promote more effective patient care. I had no idea at this point that the stages this team would go through would mimic Bruce Tuckman's stages of team development (Fig. 1) (6).

The first few meetings of the supervisor action team were chaired by the organizational development department. It decided that membership would comprise the supervisors and team leaders, with each group forming its own committee. It developed the committee's structure (Fig. 2). The supervisor action team was renamed the image governance council (IGC). Each committee elected a cochair. All members elected an IGC chair.

Other rules and procedures were decided. Meeting attendance requirements were set, and traditional meeting guidelines were developed, such as no cell-phone use during meetings. Bylaws were created, including a 2-y term of office for the chair and cochairs. Guiding principles were formulated, including...

- To focus on issues specific to the imaging department.

- To promote a satisfying work environment and quality of service consistent with the mission, vision, and values of Cedars-Sinai Medical Center.

- To identify and act on system or process issues impairing work performance.

- To cultivate respectful communication, a positive team culture, and improved leadership skills.

- To promote a culture of accountability in which all members view their participation as critical to quality outcomes.

The IGC decided that there would be focused lectures on leadership development and that their collective goal would be to work on employee recognition-an opportunity that was identified in the last employee engagement survey.

At the end of the first year, The IGC leaders reported overall satisfaction with the team. They were pleased that the meetings were well attended, but only a few members managed to get to the meetings on time, decreasing the team's effectiveness.

\section{IN THE STORMING STAGE: 1 TO 2 YEARS LATER}

The next annual employee engagement survey of the hospital indicated that staff did not feel valued. The imaging department did not meet productivity goals or other efficiency and growth goals. The supervisors had received their first review using the new, weighted, annual review tool, and most did not receive the glowing evaluation that they were used to. The IGC leaders sent an anonymous survey to all members.

This survey indicated that the IGC members liked the professional development and management lectures but were 


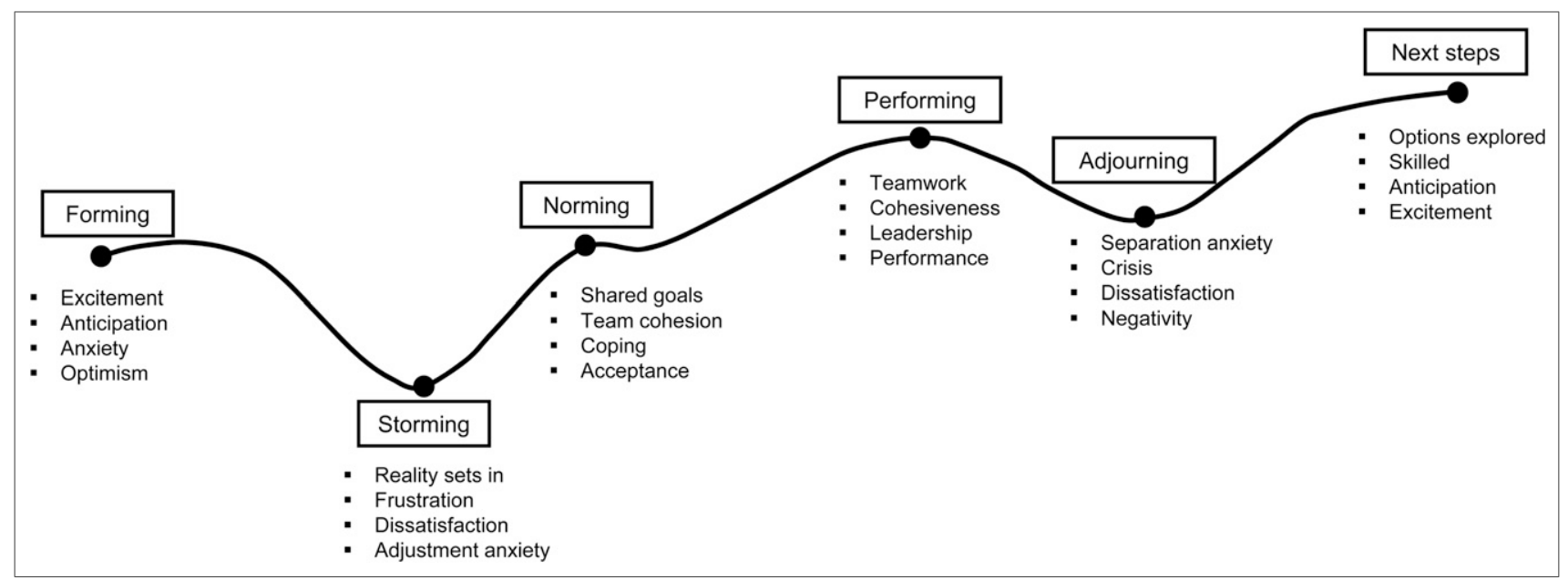

FIGURE 1. Tuckman's stages of development.

significantly disappointed in the less than stellar employee engagement survey results and failure to meet departmental goals. They believed that their ADs did not support them and that the IGC was not productive.

On the basis of the survey results, I added the IGC chair to the management team. This step would allow bidirectional feedback between the management team and the IGC.

The IGC chairs were given the authority to review each member's performance and commitment to the goals and objectives of the IGC. The IGC membership scored the effectiveness of the chair and cochairs. This score was added to the supervisor's review and was given a $10 \%$ weight, decreasing the ADs' weighted review to $70 \%$. The team leaders' annual review tool was revised to be consistent with the supervisors and was also weighted (70\% supervisor, 20\% AD, and 10\% IGC). White and yellow belt courses (introductory and beginning Six Sigma training) were offered to all IGC members.

The IGC members created 3 goals for themselves: improve staff productivity, improve the employee engagement survey results regarding recognition, and reduce the number of falls in the department. Each task force selected its leader. The IGC organized and sponsored a successful holiday

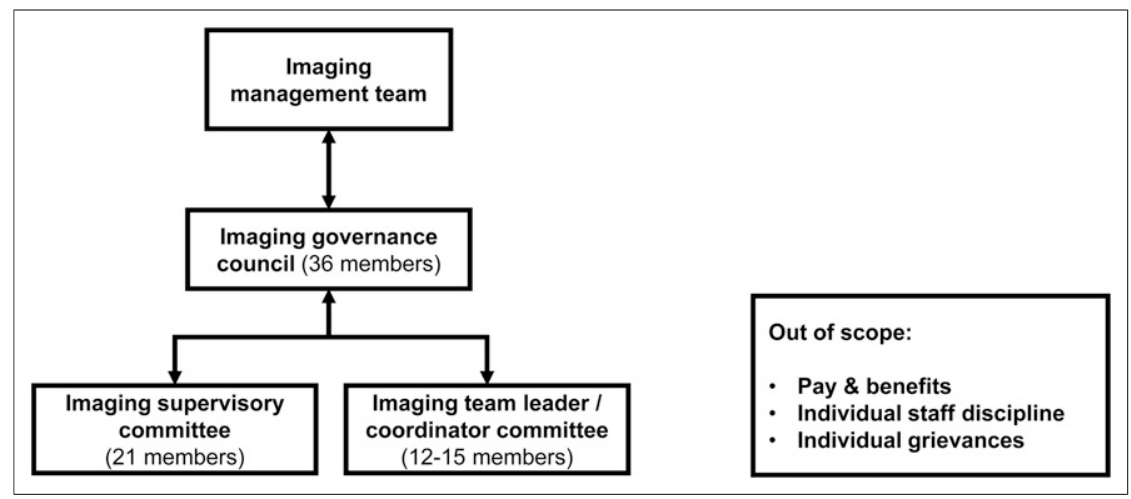

FIGURE 2. Imaging governance and committee structure. charity event to help disadvantaged community members. Per its own bylaws, it held its first biannual election of IGC officers.

At the end of year 2, department metrics indicated that 2 of the 3 goals had not been met. The annual employee engagement survey indicated that staff still did not feel recognized. The projected improved productivity did not materialize. Falls decreased and exceeded the target. The IGC review indicated that members were extremely disappointed (and emotional) about not meeting their goals. They hated the IGC. I began to doubt the wisdom of forming a self-governance team.

I reread the references on teams. Most indicated that it takes time to change culture and that all teams go through Tuckman's stages. Most failures are because the team cannot get past the storming stage. I decided this journey would continue.

I asked to attend the next IGC meeting. I read back the IGC evaluations verbatim. We discussed what was said, what was meant, what was heard, and whether the comments were constructive. After a long silence, the team began honest dialogue. They were embarrassed. They discussed how the way in which something is said can affect the outcome, but they also asked (begged would be a better term) for the IGC to end.

\section{IN THE NORMING STAGE: 3 YEARS LATER}

When the team members realized that the IGC was not going to dissolve, they started to resolve their differences. The newly elected chair focused on development of emotional intelligence (7). White and yellow belt classes, previously offered as an elective, became mandatory. Three new goals were selected, and the weights of the 
yearly evaluations were changed. The IGC review now counted for $20 \%$ of the evaluation, reducing the ADs' weight by another $10 \%$. The team began to appreciate each member's different perspectives and strengths. They started to ask each other for help and provided constructive feedback.

They organized an employee stress reduction event that included fitness classes and neck messages. Healthy-living lectures were held, with most employees attending. Their 3 goals-improving the employee engagement survey results, improving patient flow, and reducing critical errors-got traction.

\section{IN THE PERFORMING STAGE: 4 YEARS AND COUNTING}

The imaging department's employee engagement survey results were the highest in the medical center. Patient satisfaction results were the best in the hospital. Most areas reduced delays and waits by $35 \%$ despite increased patient visits. Employee safety results were strong. All departmental goals were exceeded. The imaging department exceeded its expense reduction goals. We were thrilled when the hospital adopted some of our tactics universally to improve employee engagement.

\section{CONCLUSION}

Imaging goals at our medical center have changed annually, and most have been met. Imaging has been recognized as one of the most successful departments in the medical center, based on metrics. The IGC is self-organized and performs independently. It has become an essential part of imaging leadership. Most IGC members deploy process improvement techniques and have started to develop their employees. However, few have been able to initiate these changes without effort. They struggle with setting goals for employees and holding them accountable to these goals. The health care picture is still fuzzy for some of them. Five IGC members have been promoted. This was not an experiment to determine whether Tuckman's observations of team development were accurate. There was no control group or a different model to determine the best tactic to improve performance. However, it was knowledge about these stagesthe storming stage in particular-that kept me from disbanding the" team when things seemed to be going badly.
Health care is a team sport. Each member of a team must play his or her role excellently for the team to be excellent. The supervisors, although excellent techs or clerks, were not excellent leaders. I believed that if these leaders improved collectively as one team, the imaging department could improve its health care delivery model. That is why I charted the supervisor action team. The supervisors and the team leaders created the IGC.

Through this process, I myself also developed as a leader. I delegate more responsibility and fewer tasks. I have learned that one must shift power and ownership to make teams self-organizing, independent, and effective. When independent decisions are allowed, ownership is developed. The management structure needs to be dismantled to reduce "command and control." If responsibility is given to others without giving them the power to execute and be accountable, the leader retains the power. If this transition is done too fast, most will object, lack context and direction, and believe there is a leadership void. I learned not to give up when outcomes are not as imagined; in that case, it is the tactic, not the vision, that must be changed.

I learned that the collective action of a highly developed team can achieve anything if you let them.

\section{DISCLOSURE}

No potential conflict of interest relevant to this article was reported.

\section{REFERENCES}

1. How the wrong people get promoted and how to change it. Fast Company website. https://www.fstcompany.com/3045453/how-the-wrong-people-get-promoted-andhow-to-change-it. Published April 29, 2015. Accessed August 13, 2019.

2. Diagnosis Related Group (DRG) law and legal definition. USLegal website. https://definitions.uslegal.com/d/diagnosis-related-group-drg/. Accessed August 6, 2019.

3. Blakeman C. Why self-managed teams are the future of business. Inc. website. https://www.inc.com/chuck-blakeman/why-self-managed-teams-are-the-futureof-business.html. Published November 25, 2014. Accessed August 6, 2019.

4. Stagl KC, Salas E, Burkes CS. Best practices in team leadership. In: Conger J, Riggio R, eds. The Practice of Leadership. San Francisco, CA: Jessey-Bass; 2007.

5. Orsburn JD. Self-Directed Work Teams: The New American Challenge. Homewood, IL: Business One Driven; 1990.

6. Tuckman BW. Developmental sequence in small groups. Psychol Bull. 1965;63:384-399.

7. Bradberry T, Greaves J. Emotional Intelligence 2.0. San Diego, CA: Talent Smart; 2009. 